\title{
Proceeding
}

8th INSHS International Christmas Sport Scientific Conference, 5-7 December 2013. International Network of Sport and Health

Science. Szombathely, Hungary

\section{Agings and the parameters in static postural way}

\author{
JAN CVECKA ${ }^{1,2}$, JAN CACEK ${ }^{1}$, JAN ONDRACEK ${ }^{1}$ \\ ${ }^{1}$ Faculty of Sport Studies, Masaryk University, Brno, Czech \\ ${ }^{2}$ Faculty of Physical Education and Sport, Comenius University, Bratislava, Slovakia
}

\begin{abstract}
Cvecka, J., Cacek, J. \& Ondracek, J. (2014). Agings and the parameters in static postural way. J. Hum. Sport Exerc., 9(Proc1), pp.S533-S537. There is strong scientific evidence from research trials that aging is associated with loss of muscle mass and decline of neuromuscular abilities. Postural stability is an important neuromuscular ability for the maintenance of upright posture as well as maintaining equilibrium or balance while performing movements and everyday activities. Postural stability is also an important factor in elderly people where postural instability is a major contributor to falls. In our study young and elderly subjects stood quietly in upright posture with parallel positions of their feet and opened eyes on a force platform and performed 3 trials with each trial lasting $30 \mathrm{~s}$. The effects of healthy aging on postural sway parameters were studied. We found that age-related changes in postural sway mostly affect the velocity of the center of pressure movement and the mean amplitude center of pressure movement during static postural sway test. Key words: AGING, PERFORMING MOVEMENTS
\end{abstract}

Corresponding author. Faculty of Sport Studies, Masaryk University, Brno, Czech.

E-mail: cvecka@fsport.uniba.sk

8th INSHS International Christmas Sport Scientific Conference, 5-7 December 2013. International Network of Sport and Health Science. Szombathely, Hungary.

JOURNAL OF HUMAN SPORT \& EXERCISE ISSN 1988-5202

(c) Faculty of Education. University of Alicante

doi:10.14198/jhse.2014.9.Proc1.43 


\section{INTRODUCTION}

Postural steadiness is the dynamics of postural control system associated with the maintenance of balance during quiet standing (Chiari, 2002). The ability to maintain postural stability represents a ground stone for the fundamental human movement - gait as well as for other important daily functional activities (Horak, 1989). Postural stability is also an important factor in elderly and in patients with certain pathologies, as postural instability is one of the major contributors for falls (Johanson, 1991). Falls related to postural instability are the main reason of injuries in aged population (WHO, 2007). There is strong statistical evidence that approximately $30 \%$ of people aged 65 years and more suffer from repeated falls (Blake, 1988). The incidence of falls in people above 70 has increased to up to $40 \%$ (Stalenhoef, 2002). Falls are responsible for more than $40 \%$ of all deaths caused by injuries (Rubenstein, 2006) and more than $20 \%$ of elderly who received serious injury resulting from a fall dies within a year (Zuckerman, 1996).

The regulation of balance integrates outputs from the visual, vestibular and somatosensory systems (Prieto, 1996). Decreased efficiency of the postural control in elderly may reflect biological processes of neuromuscular aging, as well as age-related changes in the sensorimotor systems (Horak, 1989; Sarabon, 2013). Therefore the quantification of age-related changes in postural stability may bring helpful information for understanding the mechanisms of aging process and may be useful also in identifying elderly persons at risk of falling (Sarabon, 2013). The proper understanding of balance control mechanisms is also important in designing efficient intervention program for decreasing the risk of falling and improving the performance of everyday activities in elderly and patients with postural system disorders. Therefore the aim of this study was to evaluate the changes in basic metric characteristics of postural stability related to age.

\section{METHODS}

\section{Subjects}

Sixty-six volunteers were divided into two groups. The first group consisted of young individuals $(n=31,18$ females and 13 males, age: $24.2 \pm 2.9$ years; weight $60.3 \pm 10.0 \mathrm{~kg}$, height $1.69 \pm 0.075 \mathrm{~m}$ ), whereas the second one of elderly individuals $(n=35,22$ females and 13 males, age: $65.6 \pm 4.1$ years; weight $72,4 \pm$ $12.6 \mathrm{~kg}$, height $1.65 \pm 0.079 \mathrm{~m}$ ). None of the participants reported any musculoskeletal or neurological disorder, chronical or acute alcohol consumption, or use of medications that would compromise test procedures of postural performance. The study was approved by the Ethics Committee of Faculty of Sport Studies, Masaryk University, Brno, Czech Republic and was in compliance with the Helsinki Declaration. An informed consent form was read and signed by each of the subjects prior to the investigation.

\section{Diagnostic protocol}

Before the postural sway testing, the subjects were asked to self-select a parallel feet position on the force platform and to stand quietly with the hands placed on the hips. All subjects were unshod wearing socks. Verbal instruction to the subjects was "to stand quietly with a gaze straight ahead at the target" (Figure 1). The target - a black spot was placed $1,5 \mathrm{~m}$ in front of the subject in eye height. Postural sway was measured in three trials, each of the trials lasted $30 \mathrm{~s}$. There were 30-s rest intervals between the trials. Subjects were free to either stand relaxed or make several slow steps between the trials. Ground reaction forces were recorded by a strain gauge based stabilographic platform (Fitro SwayCheck, Fitronic, Bratislava, Slovakia) on which the subjects stood. Analogue signal from the platform were digitized at the frequency of $100 \mathrm{~Hz}$ and saved for off-line processing. The raw data of the force platform allow computing two-dimensional time-space characteristics of the center of pressure (COP) in the anterio-posterior and medio-lateral directions. Two basic COP parameters were analyzed: mean distance of COP computed from 
the components of center of pressure excursions (Figure 2) and mean velocity of COP movement. Independent-samples t-test was used to evaluate the differences between the groups of young and elderly subjects. A average of three performed trials, average of best two trials as well the best trial was use for statistic analyses. The level of statistical significance was set at 0.05 .

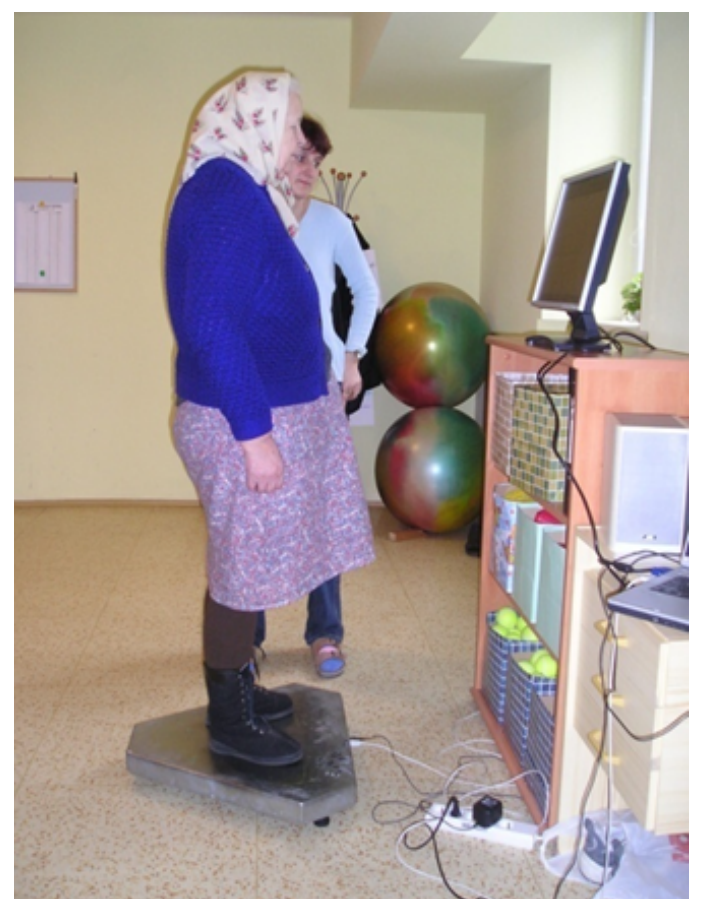

Figure 1. Postural stability testing of an elderly subject

DISTANCE: 18,060

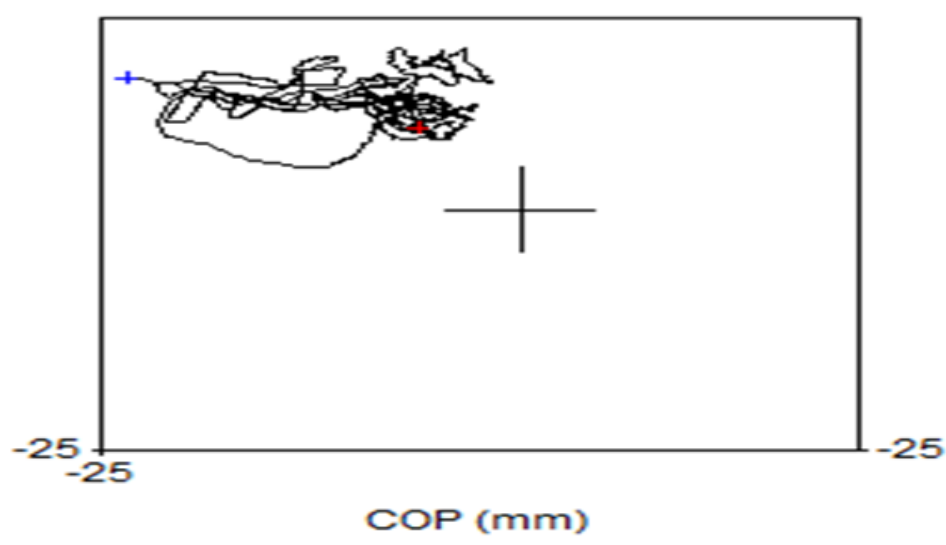

Figure 2. Stabilogram or plantar trajectory of COP

\section{RESULTS}

Statistical analyses of mean COP distance show significant differences between young and elderly subjects in the comparison of average values of all trials, average values of best two trials and in the comparison of best trials. The mean COP distance calculated from average values from all trials was in young and elderly 
subjects $3.97 \pm 1.1 \mathrm{~mm}$ and $4.22 \pm 1.37 \mathrm{~mm}$ respectively. These results present a significant $6.16 \%$ difference $(p<0.05)$. The average of best two trials was $3.41 \pm 0.9 \mathrm{~mm}$ in young subjects and $3.81 \pm 1.31$ $\mathrm{mm}$ in elderly. The difference $11.77 \%$ is statistically significant at the level of 0.05 . The largest differences were observed in comparison of best trials. In this analysis the mean COP distance in young and elderly subjects was $3.04 \pm 0.83 \mathrm{~mm}$ and $3.45 \pm 1.22 \mathrm{~mm}$ respectively. The difference $13.59 \%$ is statistically significant at the level of 0.05 .

In the comparison of mean COP velocity identical procedure as in the analyses of mean COP distance was used. The mean COP velocity calculated from average values from all trials was in young and elderly subjects $11.88 \pm 2.63 \mathrm{~mm}$ and $13.38 \pm 6.81 \mathrm{~mm}$ respectively. These results $(19.62 \%)$ present the largest difference across the mean COP velocity comparison with statistical significance at the level of 0.05 . The average of best two trials was $10.69 \pm 2.57 \mathrm{~mm}$ in young subjects and $12.77 \pm 6.50 \mathrm{~mm}$ in elderly. The difference $19.50 \%$ is statistically significant at the level of 0.05 . In the analysis of the best trials the mean COP velocity in young and elderly subjects was $10.25 \pm 2.59 \mathrm{~mm}$ and $12.17 \pm 6.30 \mathrm{~mm}$ respectively. The difference $18.72 \%$ is statistically significant at the level of 0.05 .

Table 1. Mean values \pm standard deviation of mean COP distance and mean COP velocity during 30 s static balance test young and elderly subjects

\begin{tabular}{|c|c|c|c|c|c|}
\hline \multicolumn{3}{|l|}{ COP parameter } & \multirow[b]{2}{*}{ elderly } & \multicolumn{2}{|c|}{ young versus elderl } \\
\hline \multirow{4}{*}{$\begin{array}{c}\text { mean COP distance } \\
{[\mathrm{mm}]}\end{array}$} & \multicolumn{2}{|r|}{ young } & & $\Delta(\%)$ & t-test \\
\hline & avr & $3.97 \pm 1.1$ & $4.22 \pm 1.37$ & 6.16 & $p<0.05$ \\
\hline & Best 2 & $3.41 \pm 0.90$ & $3,81 \pm 1.31$ & 11.77 & $p<0.05$ \\
\hline & best & $3.04 \pm 0,83$ & $3.45 \pm 1.22$ & 13.59 & $p<0.05$ \\
\hline \multirow{3}{*}{$\begin{array}{c}\text { mean COP velocity } \\
{[\mathrm{mm} / \mathrm{s}]}\end{array}$} & avr & $11.88 \pm 2.63$ & $13.38 \pm 6.81$ & 19.62 & $p<0.05$ \\
\hline & best 2 & $10.69 \pm 2.57$ & $12.77 \pm 6.50$ & 19.50 & $p<0.05$ \\
\hline & best & $10.25 \pm 2.59$ & $12.17 \pm 6.30$ & 18.72 & $p<0.05$ \\
\hline
\end{tabular}

Displayed values represent statistical analysis of average from all three performed trials, average of best two trials the best trial. Statistical significance was analysed using independent-saplest-test. The level of statistical significance was al 0.05

\section{DISCUSSION AND CONCLUSIONS}

The primary focus of this study was to evaluate the age-related changes in postural stability by comparing the basic parameters of static sway measured by a device based on COP-excursion recording during quiet standing with open eyes.

Mean distance of COP excursion and mean COP velocity were evaluated. We found out that both evaluated parameter mean distance of COP excursion and mean COP velocity do change significantly with the age. Both parameters increased with age significantly. Highest differences were observed in comparison of best trials for the mean COP distance and in comparison of average values of all trials for mean COP velocity.

Our findings are generally in agreement with Prieto et al. (1996), who found changes in both mean distance of COP and mean COP velocity related to age in open eyes measurements. According to Berger (2010) findings these age-related changes have some common origins encompassing loss of muscle mass, 
muscle fibre type transformation, loss of sensorimotor functions, reduction in the number of neurons, and neuroplasticity changes. Other studies found connections between level of postural stability with increased incidence of falls (Brocklehurst, 1982). On the other hand, several studies have shown that these negative changes can be effectively compensated by the use of various movement interventions (Lord, 1996). Skelton (1999) confirmed that properly designed intervention program containing challenging balance exercises is effective in decreasing the risk of falls in elderly people. Following our findings we can conclude, that postural stability testing provides objective information for researchers and clinicians to evaluate the neuromuscular, senzorimotor and functional changes related to the age. This information provides a useful tool for the identifying of the risk of falls and/or for recommendation of suitable movement therapy.

\section{REFERENCES}

1. Berger, M.J. \& Doherty, T.J. (2010). Sarcopenia: prevalence, mechanisms, and functional consequences. Interdisciplinary topics in gerontology, 37, pp.94-114.

2. Blake A, et Al. (1988). Falls by elderly people at home: prevalence and associated factors. Age Ageing, 17, pp.365-372.

3. Brocklehurst, J.C., Robertson. D. \& James-Groom, P. (1982). Clinical correlates of sway in old age-Sensory modalities. Age Ageing, 11, pp.1-10.

4. Horak, F.B., Shupert, C.L., Mirka, A. (1989). Postural dyscontrol in the elderly: A review. Neurobiol Aging, 10, pp.727-738.

5. Chiari, L., Rocchi, L. \& Cappello, A. (2002). Stabilometric parameters are affected by anthropometry and foot placement. Clin Biomech, 17, pp.666-677.

6. Johansson, R. \& Magnusson M. (1991). Human postural dynamics, CRC Crit. Rev Biomed Eng, 18, pp.413-437.

7. Lord, S.R., Ward, J.A. \& Williams, P. (1996). Exercise effect on dynamic stability in older women: a randomized controlled trial. Arch Phys Med Rehabil, 77, pp.232-6.

8. Prieto, T.E., Myklebust, J.B. \& Hoffmann, R.G. (1996). Measures of postural steadiness: differences between healthy young and elderly adults. IEEE Trans Biomed Eng 43m, pp.956-966.

9. Rubenstein, L.Z. (2006). Falls in older people: epidemiology, risk factors and strategies for prevention. Age Ageing, 35-S2, pp.ii37-ii41.

10. Sarabon, N., Loefler, S., Cvecka, J., Sedliak, M. \& Kern H. (2013). Strength training in elderly people improves static balance: a randomized controlled trial. Eur J of Trans Myol, 23(3), pp.85.

11. Skelton, D., Dinan, S., Campbell, M. \& Rutherford, O. (2005). Tailored group exercise (Falls Management Exercise-FaME) reduces falls in community-dwelling older frequent fallers (an RCT). Age Ageing, 34(6), pp.636-9.

12. Stalenhoef, P.A., et al. (2002). A risk model for the prediction of recurrent falls in community dwelling elderly: A prospective cohort study. Journal of Clinical Epidemiology, 55(11), pp.10881094.

13. World Health Organization. A guide for population-based approaches to increasing levels of physical activity: implementation of the WHO Global Strategy on Diet, Physical Activity and Health. Geneva, World Health Organization, 2007.

14. Zuckerman, J.D. (1996). Hip fracture. New England Journal of Medicine, 334(23), pp.1519-1525. 